\title{
THE COMPUTATIONAL STUDY OF A NOVEL SECONDARY STEELMAKING REACTOR
}

\author{
Debasish Chatterjee ${ }^{1}$ \\ ${ }^{I}$ Department of Metallurgical \& Materials Engineering, Indian Institute of Technology Roorkee (Uttarakhand, India)- \\ 247667
}

\begin{abstract}
Computational study via Fluent software of a novel secondary steelmaking metallurgical reactor has been done which will be so versatile that all grades can be produced by this reactor with moderate mixing and decarburization. Mixing time has been calculated for model reactor. Slag eye also has been computed.
\end{abstract}

Keywords: - Novel reactor, steel, ladle, mixing, decarburization

\section{INTRODUCTION}

Along with globalization of market the competition among manufacturer especially steel has been increased. From that point not only quality of steel is important. The versatility of the process is also important. Because it is inter related with capital expenditure (CAPEX) and operation expenditure
(OPEX) of a process. It has a vital role in steelmaking process. In producing high quality steel, gas bubbling is one of the essential techniques. This is because it can enhance the reaction rates between the slags and melt and/or melt and powder, eliminate the thermal and/or concentration gradient, and remove nonmetallic inclusions [1].
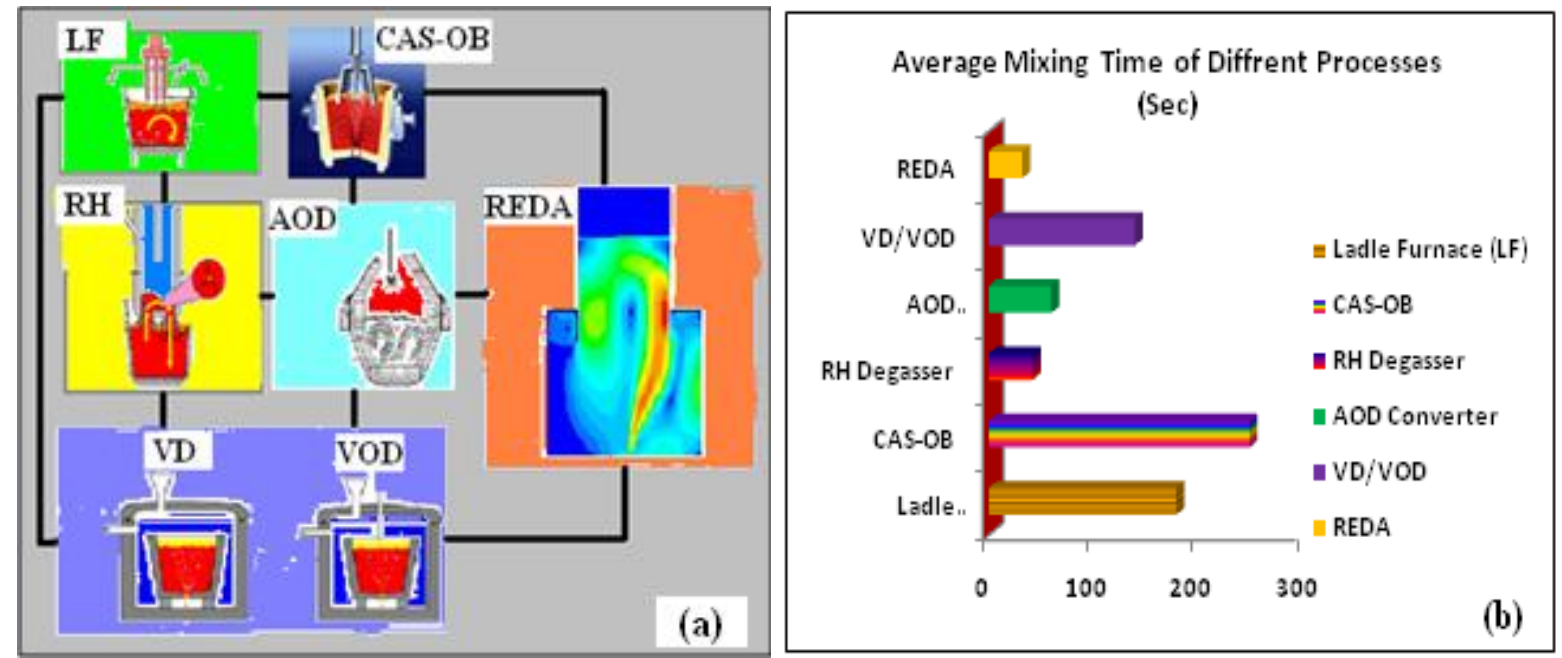

Fig 1 (a) Schematic diagram of different secondary steelmaking processes (b) Average mixing time of different secondary steelmaking processes [1-5]

In recent times the demand of ultra-low carbon steel (ULCS) with improved mechanical properties such as good ductility and good workability has been increased as it is used to produce cold-rolled steel sheets for automobiles. For producing ULCS efficiently, it is necessary to improve the productivity of the vacuum degassers such as RH, DH and tank degasser. Recently, it has been claimed that using a new process, called REDA (revolutionary degassing activator), one can achieve the carbon content below $10 \mathrm{ppm}$ in less time [2]. During the last four decades the AOD process has been established as a reliable and efficient refining process in stainless steel making. Compared to other injection geometries, e.g. bottom blowing, the injection of process gases (oxygen, nitrogen, argon) through sidewall tuyeres shows advantages in mixing effectiveness [3]. CAS (composition adjustment by sealed argon bubbling systems), bubbles argon gas into molten steel through a porous plug or submerged lance. The rising gas/liquid plume creates an opening in the top slag cover, over which a refractory lined cylinder is lowered into the steel. The essential idea is to make bulk alloy additions inside this slag-free region under an inert atmosphere [4]. The Schematic diagram of different secondary steelmaking processes and average mixing time of different secondary steelmaking processes is shown in fig 1 (a) and (b) respectively. 


\section{PRESENT STUDY}

The objective of the present study is to develop a process which will be so versatile that all grades can be made by this secondary steelmaking reactor by minimum investment of capital and operative cost and mixing, decarburization will be fast.

\subsection{Novel Secondary Steelmaking Reactor}
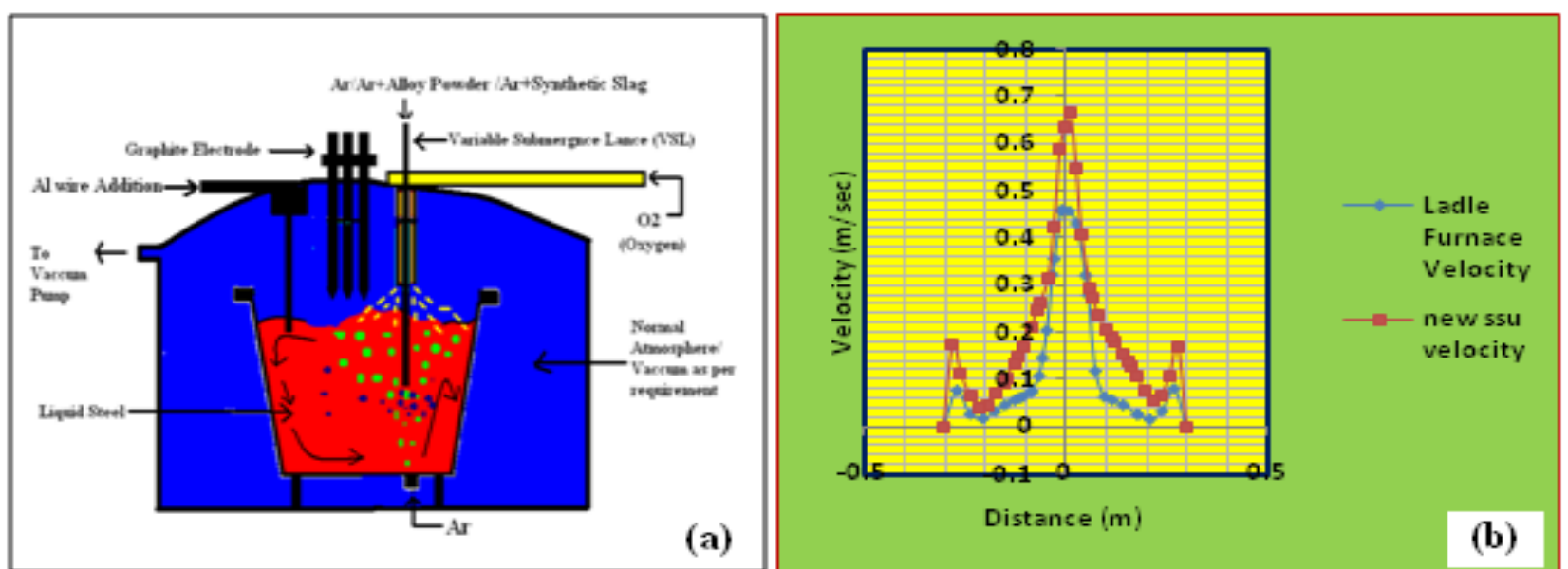

Fig 2 (a) Schematic diagram of novel secondary steelmaking reactor (b) Velocity magnitude plot along radial direction for ladle furnace and new secondary steelmaking reactor

The Novel Reactor consists of a tank along with graphite electrode for arcing. Mainly it will consist of a variable submergence lance (VSL) for purging argon gas from top along with bottom purging. The alloy powder also can be induced from the top lance at submergence condition. The flow rate of argon from the top lance can be adjusted along with submergence and the requirement of the process. The description of the reactor is explained schematically in fig 2 (a). In addition the tank can be evacuated as per requirement and al wire injection can be done from the top.

\section{RESULTS \& DISCUSSION}

\subsection{Velocity Profile}

A discrete phase model (Fluent 6.3) has been simulated where argon is purging at a low rate from the bottom and comparatively higher gas flow rate applied from the top lance. The velocity along a line at position of $\mathrm{z}=0.4 \mathrm{~m}$ where ( $\mathrm{z}$ ladle $=0.6 \mathrm{~m}$ and $\mathrm{D}$ ladle $=0.6 \mathrm{~m}$ ) has been plotted in the fig. 2 (b). It is seen from the figure that new reactor has higher velocity flow compare to conventional ladle furnace.
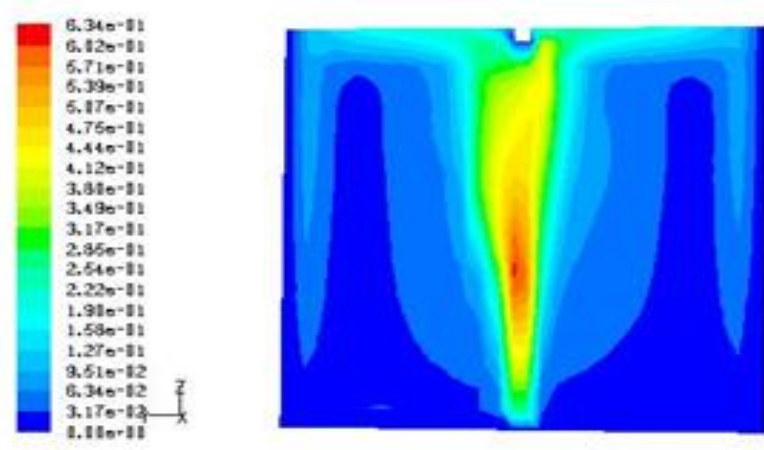

Ladle Funace
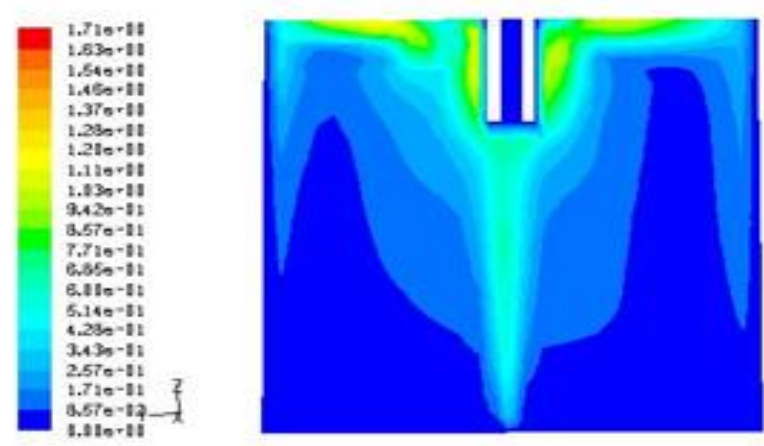

New Secondary Steelmaking Reactor

Fig .3 Velocity contour plots for ladle furnace and new secondary steelmaking reactor

The velocity contour has been plotted in fig. 3 . The contour plot shows that new reactor has high velocity profile 1.7 $\mathrm{m} / \mathrm{sec}(\max )$ compare to ladle furnace containing velocity $0.63 \mathrm{~m} / \mathrm{sec}(\max )$. The velocity profile remains same for both cases. Only the magnitude of velocity will change. It suggests that the flow of fluid in the new reactor can be adjusted by changing the flow rate of argon and the submergence of lance in the ladle. It is the key of new reactor which can control kinetics, mixing and decarburization of different processes. It can be used in vacuum also with proper safety. 


\subsection{Mixing Time}

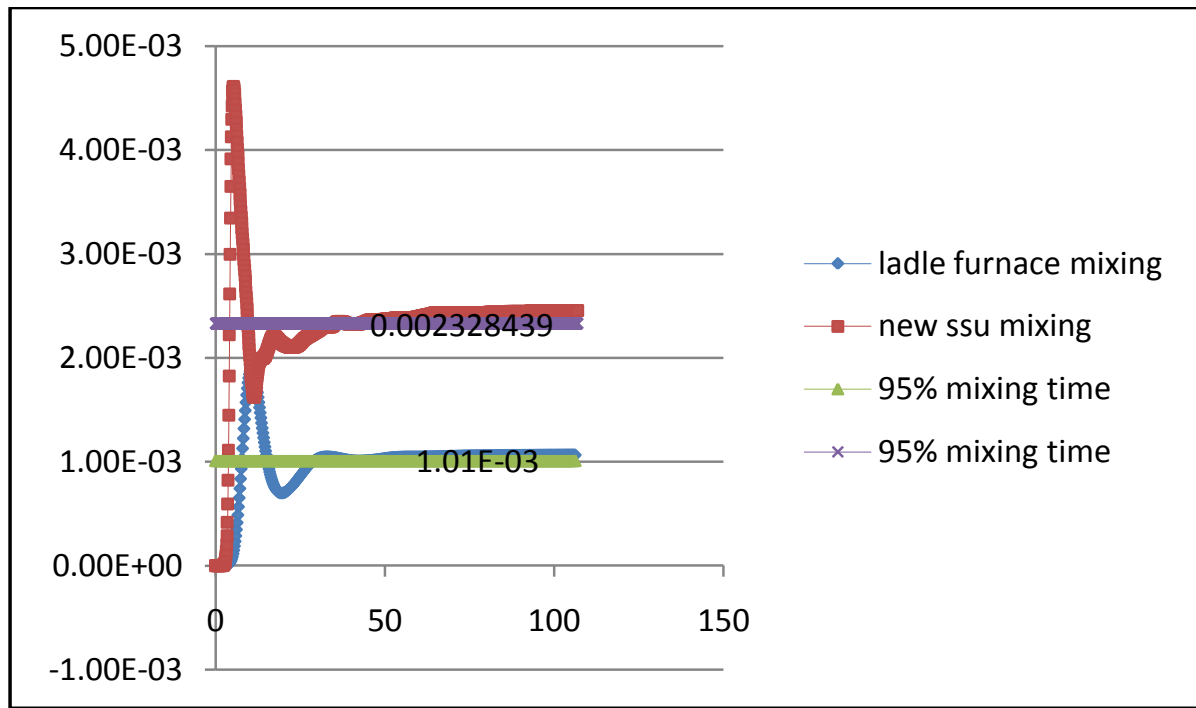

Fig 4 Mixing time for ladle furnace and new secondary steelmaking reactor

The mixing time has been calculated for both the cases. The $95 \%$ mixing time of new steelmaking reactor is $30 \mathrm{sec}$ where as for ladle furnace it is $50 \mathrm{sec}$. It means that the new reactor has high efficiency in terms of mixing of alloys within the melt i.e. in normal condition and vacuum condition also. The drawback of VD (vacuum degassing) and VOD (vacuum oxygen decarburization) is that the mixing process i.e. decarburization process is very slow. But in the new process along with fast mixing process will help to fast decarburization is expected. Because it will produce enormous bubbles in vacuum which will indirectly increase the circulation surface of decarburization. The decarburization rate can be controlled by changing the submergence of the lance within the melt and also by controlling the flow rate of argon within the melt. The

\subsection{Slag Eye}

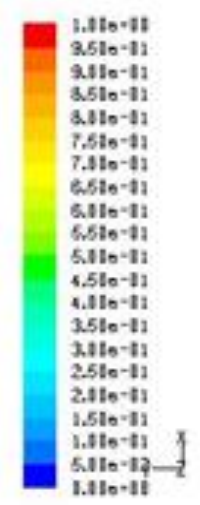

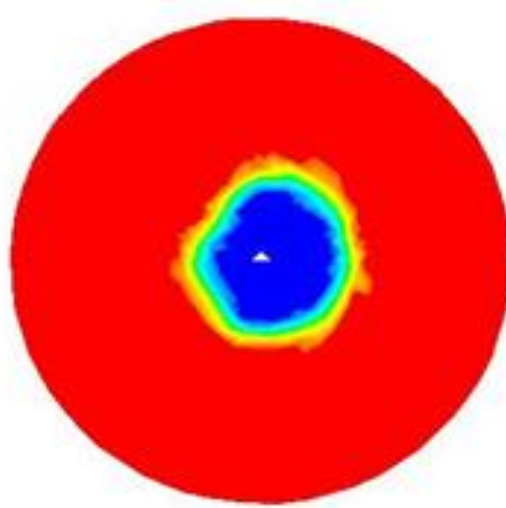

Ladle Funace reactor will have the facility to adjust the temperature by heating through electrode and by impinging coolant from the top variant submergence lance. Al wire can be inserted for alloying the metal and further de-oxidation of the melt. Inclusion can be controlled by addition of synthetic slag/ shape controlled powder from the top lance. Vacuum of the melt can be controlled as per requirement also. The other vacuum degassing process like RH and REDA has fastest mixing time. But in terms versatility, capital expenditure, operation cost it cannot be compared with the new reactor which has fast mixing as well as low CAPEX and OPEX. The new process can be compared with CAS-OB (slowest mixing) and AOD converter also for making all grades of steel.

Fig 5 Slag eye for ladle furnace and new secondary steelmaking reactor 
The slag eye has a big role on re-oxidation of the melt. Discrete phase model coupled with VOF (volume of fluid) simulation has been done to compute the slag ye. Both of the reactors have same slag eye diameter $0.2 \mathrm{~m}$. So it can say that the re-oxidation tendency of the two reactor melt will be same. The slag eye has been shown in the fig.5 where red color portion is the $100 \%$ volume fraction of slag (here oil use as a simulating fluid in place of slag) and blue color region is the $100 \%$ volume fraction of steel (here water use as a simulating fluid in place of steel). The wateroil mixture i.e. steel-slag mixture volume fraction has been indicated by intermediate colors.

\section{CONCLUSIONS}

- The novel metallurgical reactor will be efficient enough in terms of mixing, decarburization, inclusion control and shape control etc.

- The new reactor will be commercially more effective than the other secondary steelmaking unit in terms of CAPEX and OPEX.

\section{FUTURE WORK}

In future the author wants to do water modeling study of the novel unit and wants to implement it for commercial production.

\section{REFERENCES}

[1] Ki-Su Lee, Won-Oh Yang, Young-Geun Park and Kyung-Woo Yi: Metals and Materials, 461, 6(2000)

[2] M. K. Mondal , N. Maruoka , S. Kitamura , G. S. Gupta , H. Nogami , H. Shibata: Trans Indian Inst Met, 321, 65(2012)

[3] Christian Wuppermann, Nils Giesselmann, Antje Ruckert, Herbert Pfeifer, Hans-Jürgen Odenthal and Erich Hovestadt: ISIJ Int., 1817, 52 (2012)

[4] D. Mazumdar and R.I.L. Guthrie : Met. Trans. B, 649, 24B(1993)

[5] M. Warzecha, J. Jowsa, T. Merder: Metallurgija, 227, 46 (2007) 